\title{
UNIVERSITYOF
}

FORWARD

THINKING

WESTMINSTER用

WestminsterResearch

http://www.westminster.ac.uk/westminsterresearch

\section{Architectural self-fabrication}

Cascone, P., Galdi, F., Giglio, A. and Ciancio, E.

This is an accepted manuscript of an article published by Taylor \& Francis in the International Journal of Parallel, Emergent and Distributed Systems, 32 (sup1), pp. S39S53.

The final definitive version is available online:

https://dx.doi.org/10.1080/17445760.2017.1390108

(C) 2018 Taylor \& Francis

The WestminsterResearch online digital archive at the University of Westminster aims to make the research output of the University available to a wider audience. Copyright and Moral Rights remain with the authors and/or copyright owners.

Whilst further distribution of specific materials from within this archive is forbidden, you may freely distribute the URL of WestminsterResearch: ((http://westminsterresearch.wmin.ac.uk/)).

In case of abuse or copyright appearing without permission e-mail repository@westminster.ac.uk 


\title{
Architectural Self-Fabrication
}

\author{
Author: Paolo Cascone - (COdesignLab) \\ Co-authors: Flavio Galdi, Andrea Giglio, Elena Ciancio
}

COdesignLab, Naples, Italy

paolo@co-design-lab.net

Paolo Cascone was born in Italy (1976) and grew up between West Indies and East Africa, graduated in architecture in Naples and started his research between advanced design, digital fabrication and self-construction during his master at the architectural association (London-UK) in sustainable design and continued it while accomplishing a $\mathrm{PhD}$ in environmental engineering at the university of Rome. In the past years Paolo has developed interdisciplinary projects with international firms and applied researches in the field of environmental parametric design and smart construction. He has been teaching as Sssociate Professor at the ENSA Paris / Malaquais and at the Ecole Speciale d'Srchitecture of Paris where he founded COdesignLab. In year 2013 he founded the Urban FabLab research laboratory of urban ecologies and digital fabrication. Paolo has been lecturing widely in schools of architetcture such as ETSAM-Madrid, Renssaeler Polytechnic-New York, Sci-Arc-Los Angeles, AHO - Oslo, Insa Strasbourg, IUAV- Venice etc. he is now reseaearch fellow at Architecture Computing and Technlogy Lab of the Mialn Polytechnic. His work has been published on international reviews such as Domus, Mark, Architecture D'Aujourd-hui, Abitare, A+U etc. In 2016 Paolo has been selected for the XXIst Triennale di Milano International Exhibition (XX1T), entitled 21st Century. Design After Design and he has been recently nominated Scientific Director of the Open Design School of Matera 2019 European Capital of Culture. 


\section{Architectural Self-Fabrication}

The paper will focus on the role of computational design and digital fabrication in the processes of urban and architectural self-regeneration of existing infrastructures and buildings. Taking inspiration from some of the concepts mentioned in Christopher Alexander's essay "Systems generating systems" (1968), the Architectural Fabrication research agenda aims to introduce ways in which systems thinking and computer aided manufacturing could be most directly applied to build environments. Hacking architectural spaces evolving their genetic spatial and structural codes is confronting to the idea of optimizing resources involving inhabitants rather than generating other top down architectural solutions. In the last decades as emerged from the book of Mario Carpo "The Digital Turn in Architecture" the digital shift in architectural design has generated a new discipline with the aim to define an innovative way to bridge the notion of nature with the one of teknè. From such cultural milieu many research agenda were focusing on the concepts of morphogenesis and evolutionary thinking inspired by the work of French philosophers Gilles Deleuze and Felix Guattari based on the theory of complex systems. Despite this interest in bridging an evolutionary approach with the notion of emergent technologies in architecture, well described in the book "The Architecture of Emergence" of Michael Weinstock, only a very few researches have investigated on the potential of computational design as a driver for the ecological rehabilitation of existing infrastructures. As the computational designers were so worried to claim for a new aesthetical identity of their discipline a new opportunity is emerging for applying this evolutionary approach in order to hack existing structures.. This idea of living infrastructures is related to the possibility of developing contextual algorithms in order to customize standard solutions with a post-human process creating diversified spatial configurations out from very rigid organizational systems. Therefore the paper will also talk about the Hacking Gomorra project as a possible paradigm of experimenting a $3 \mathrm{D}$ printing protocol for the environmental rehabilitation of a megastructural housing building in Naples (Italy).

Keywords: Environmental Parametric Design, Digital Fabrication, Craft in Design Computation, Robot-Human Collaboration 


\section{Architectural Fabrication as a discipline}

\section{An evolutionary approach to digital fabrication in architecture}

In his brief essay "indeen über organische bildung" (1806) Woflgang von Goethe anticipates some of the key concepts of an evolutionary understanding of computational design. Breaking with the Aristotelian view of dynamic organism isolating the functional behaviour from the character of the whole, Goethe establish relations between form and formation in both animate and inanimate nature. He conceptualised some of the main aspects of natural behaviour as generation, variation, interaction and iteration that have driven the role of computation in design. This evolutionary approach consists in considering a set of instructions and meta-instructions which inform the transformational activities of an overall functioning system. Some of these concepts were then analysed by the French philosopher Henri Bergson in his book Creative evolution (1907) considered a milestone of the theory of the evolution. In such book he introduces the notion of élan vital the energy that moves the life as a dynamic adaptation to a specific environment in the frame of a systematic dialectic between life and form. Later developments of such theoretical approach were studied by the French philosopher Gilles Deleuze in his book Bergsonism (1988) were he denotes an internal force, a substance in which the distinction between organic and inorganic matter is indiscernible, and the emergence of life undecidable.

\section{THENE: ARE KITS OF PARTS}

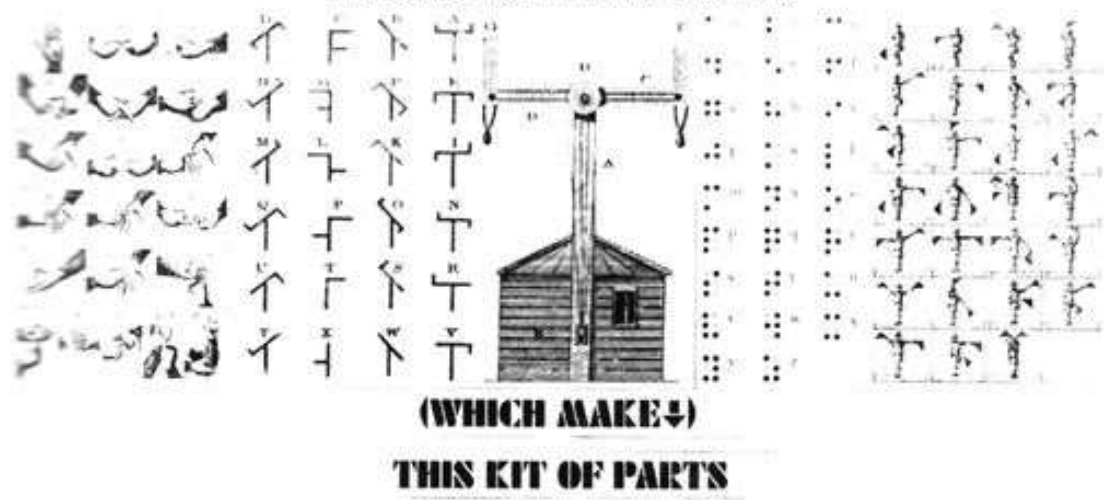

Fig 1: picture by Cristopher Alexander - Systems Generating Systems- December isuue n ${ }^{\circ} 7 / 8$ Architectural Design (1968) 
An architectural vision of such evolutionary concepts related to morphogenesis was developed by the Austrian design theorist Christopher Alexander in his text Systems Generating Systems published in an issue of Architectural Design (1968). In his article he established the notion of the unselfconscious process where he refers to the interrelation between the social context and the building, the culture and the environment. In Alexander theory architectural problems could be solved through a design process based on an iterative interpretation and responsiveness related to interrelational conditions. Such process aims to produce environments according to their cultural characteristics establishing direct cause-effects relation with forms. Therefore he describes three conditions of a generative system: the global behaviour, the components that generate such behaviour and the possible local relations between components. Unfortunately is not clearly described the process to generate a system but Alexander deines four characteristics of a system:

1.there are two ideas hidden in the word system: the idea of a system as a whole and the idea of a generating system

2.a system as a whole is not an object but a way of looking at an object. It focuses on some holistic property which can only understood as a product of interaction among parts

3 a generating system is not a view of a single thing. It is a kit of parts, with rules about the way these parts may be combined

4 almost every "system as a whole" is generated by a "generating system". If we wish to make things which function as "wholes" we shall have to invent generating systems to create them.

With this premise we consider computational design an opportunity to evolve existing buildings transforming them in things which function as "wholes". Taking inspirations also by some fo the concepts of the book "The Architecture of Emergence" of Michael Weinstock such computational design process is information based and aims to develop a generative system informed by cause effect relations between users new needs, environmental and ergonomic criteria. The genetic code of the existing infrastructure once extrapolated from the analysis of the interaction among parts becomes the initial genotype open up to possible physical variations and diversified architectural solutions. We call this process architectural hacking. The role of digital fabrication is crucial to the 
architectural hacking methodology as is considered a process of physical transformation and customization of the initial system. The idea of using the demolition materials of some of the parts of the existing infrastructure is based on metabolistic approach to architecture as a living infrastructure. This includes a set of life-sustaining spatial transformations within the users of living architectural organisms.

\section{A concrete utopia}

The project represents a paradigmatic process that envisions a possible transformation from the bottom of the extremely critical situation where several suburban areas of our cities are converging.

We talk about megastructures, which often have been created by the urban utopias, elaborated by the best European cultural 'elites' and not only since the sixties. I think about the utopian visions of Constant, the Japanese metabolism and its influence on other controversial experiences realized in France and other countries.

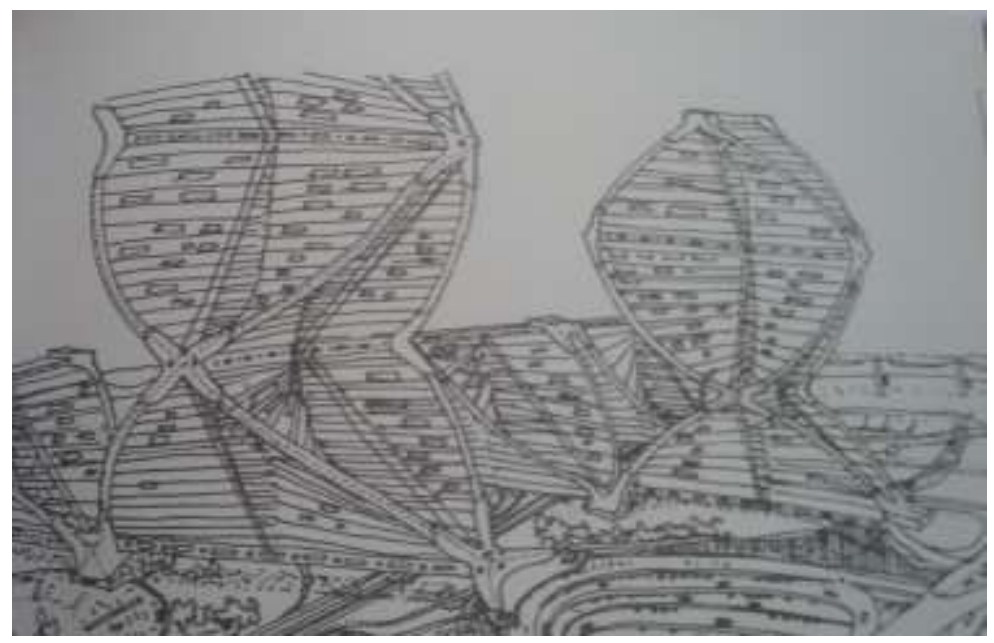

Fig2: picture by K.N. Kurokawa - Helix City (1961)- Archigram / Metabolism - Clean editions (2007)

For this reason, I don't think that replacing those utopias with others offers a valid answer to the issue. Instead, I deeply believe, that a solid theoretical approach is necessary in order to develop a process of self-regeneration of those (old) experiences and places. Nobody knows more than the people who live in that determined conditions about the tricks and the contradictions, but at the same time, people like me, who truly knows the process of collaborative design and 
self-production, are the only ones able to reconcile theory and (good) practice.

This is why, the attainability of initiatives such as Hacking Gomorra, depends on the capability to carry out high-tech micro-projects, involving successfully, the local community, with the very concrete purpose of 'hacking' the 'existing', by optimizing the resources.

\section{social innovation Vs technological innovation}

Given that the Vele of Scampia is a phenomenon that by itself would deserve an essay on urban anthropology, due to the complexity of the events connected with the urban and social decline, evolved during the time, it's very hard to bypassing the rhetoric which has characterized the debate on this side of the city. More upto-date and accurate reportages emerge from the work developed by photographers such as Mario Spada, Tobias Zylinder, etc., describe two distinct and controversial dynamics; on one side, a cynical logic of abuse of power which seeks the total control of the neighborhood by actions of privatization and illegitimately occupations of potentially collective places and by imposing gates, blockades and several other barriers; on the other side a growing drive to try and escape this 'cage' in which most of the inhabitants experience a sense of imprisonment.

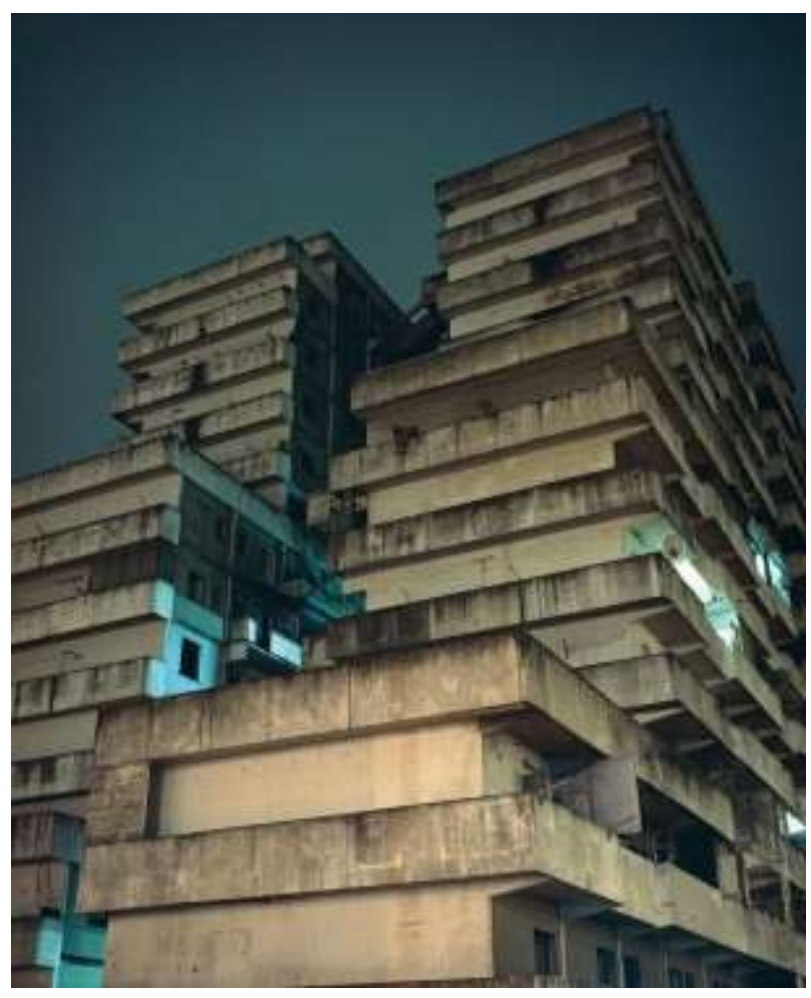

Fig 3: picture by Tobias Zielony - Vele (2010-Napoli) - http://www.liarumma.it/artists/tobias-zielony/ 
The challenge is finding a way to intercept and interpret the demands and the need of the residents, facilitating a process of auto-determination from inside. I like to remind myself that the, 25 years old, junior researcher Flavo Galdi of COdesignLab, whom I have involved in this project, was born and has grown in Scampia. Obviously, in order to be realized and shared on a wider scale, a project of this kind should be supported by a highly professional team expert in management of social conflicts. Unfortunately, we own a limited vision of the process so far because we are 'only' designers.

\section{3. the 3D printing ecologies}

For years these kind of suburban regeneration projects have been ideologically rejecting any kind of physical output and synergy with new technologies. Today a new generation of designers like me, has the cultural duty to explore the relationship between the digital and the real world, by critically analyzing all the possible repercussions on the community. The concept of 'hacking', which can be implied on any kind of building or existing infrastructure, consists of re-shaping and modifying the genetic codes of an architectural system through an evolutionary approach aimed to solve complex problems through a computational design process.

Therefore, if used with cognizance, the digital fabrication and the 3D printing technology can represent an opportunity for supporting the 'architectural fabrication', meaning the physical self-production of artifacts, generated by this bottom-up computational approach.

Just consider that the $90 \%$ of Hacking Gomorra's architectural artifacts is conceived to be realized through the $3 \mathrm{D}$ print of a mix of demolition materials and natural and autochthon materials. Even though, this arguments seems to be a merely technological speech, it actually represents a political 'manifest' that might subvert the 'building construction world' afflicted by the interests of the organized criminality. I'm deeply convinced that the action of self-construction could be a very strong medium for the upcoming identity process, turning the inhabitants more responsible and creating new micro-economies. From a 'spatial' point of view, the digital fabrication allows us to create custom-tailored components, which connect, increase or generate collective and oft productive spaces. All these connecting spatial elements are inspired by a series of concepts on the 'Function of the oblique' projects expressed in the work of Paul Virilio 
and Claude Parent.

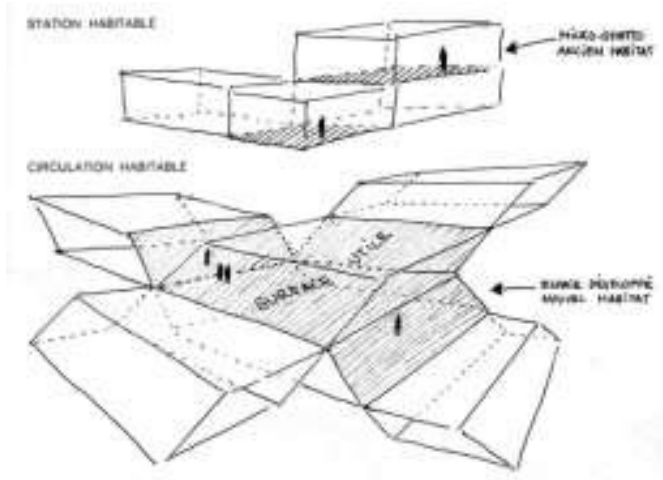

Fig 4: picture by Claude Parent and Paul Virilio - 'Function of the oblique' Vele (1963-1969) - AA Publications 1996

As mentioned, before being an urban self-regeneration project 'Hacking Gomorra' would be a generative and operative design to make process. At the same time the project wanted to be an attempt to physically translate and transport some of the quoted concepts from the Felix Guattari's book 'Trois ecologies'.

In this process, we envision the employment of environmental and structural simulation software with the aim to analyze and foresee the system's performance by mapping the contest.

Of course we constantly draw inspiration from the work of others ( such as documentaries, photojournalism, contemporary art, etc.), which have optimally narrated, through disciplines different from ours, the underway social dynamics. In our personal case, the strong inclination to connect the digital process to the architectural components through physical prototyping helps us to better understand the spatial dimension of our work.

In order to evolve our methodology we consider so invaluable the several and continuous exchanges of opinions carried on with town planners and designers such as Ugo La Pietra, author of the book 'Living the city', in which are present many of the fore mentioned themes. 


\section{Digital fabrication in architecture}

The information age, as the industrial age before it, is changing not only the way we design buildings, but also the way we construct them. If on the one hand digital technologies (computational design) are offering new scenarios on the possibilities of complex shapes and generative architecture, on the other hand the digital fabrication, as occurred for other disciplines such as biomedical or aeronautical, is evolving to make more immediate and seamless the construction of CAD models .

In this sense design and fabrication inform each other within a unique process inspiring each other for future developments, as described by Stephen Kieran in "Rethinking Refabricating Architecture.

The fabrication processes can be divided into two categories:

-subtractive manufacturing, concerning the creation of a form through the removal of material using $\mathrm{CNC}$ milling machines or laser cutters.

- additive manufacturing, concerning the construction of forms through the deposition of material layers using $3 \mathrm{~d}$ printing technology.

Both of these two categories of processing are provided by various types of technologies and CNC machines which differ, mainly, on the basis of freedom of spatial movement achievable by the tool (from "in box" $3 \mathrm{~d}$ printers we passed to 6 axis robotic arms and mini-builders ).

The potential expressed by the new digital manufacturing technologies focus on different aspects related to the construction industry:

- They have introduced the concept of mass customization conceived as the possibility of producing self-similar non-standard forms as opposed to mass production with the same production costs. This potential has been expressed in Greg Lynn's "Embryologic Houses" manifest.

- They enable technical advances that affect the manufacturability of integrated systems more easily .

- savings on production costs for the possibility of re-use of materials, saving on transport and on the use of shuttering, of labor costs and on the quantity of waste produced

- optimizing the use of materials, approaching the almost perfect weight-strength ratio through the use of FEM software. 


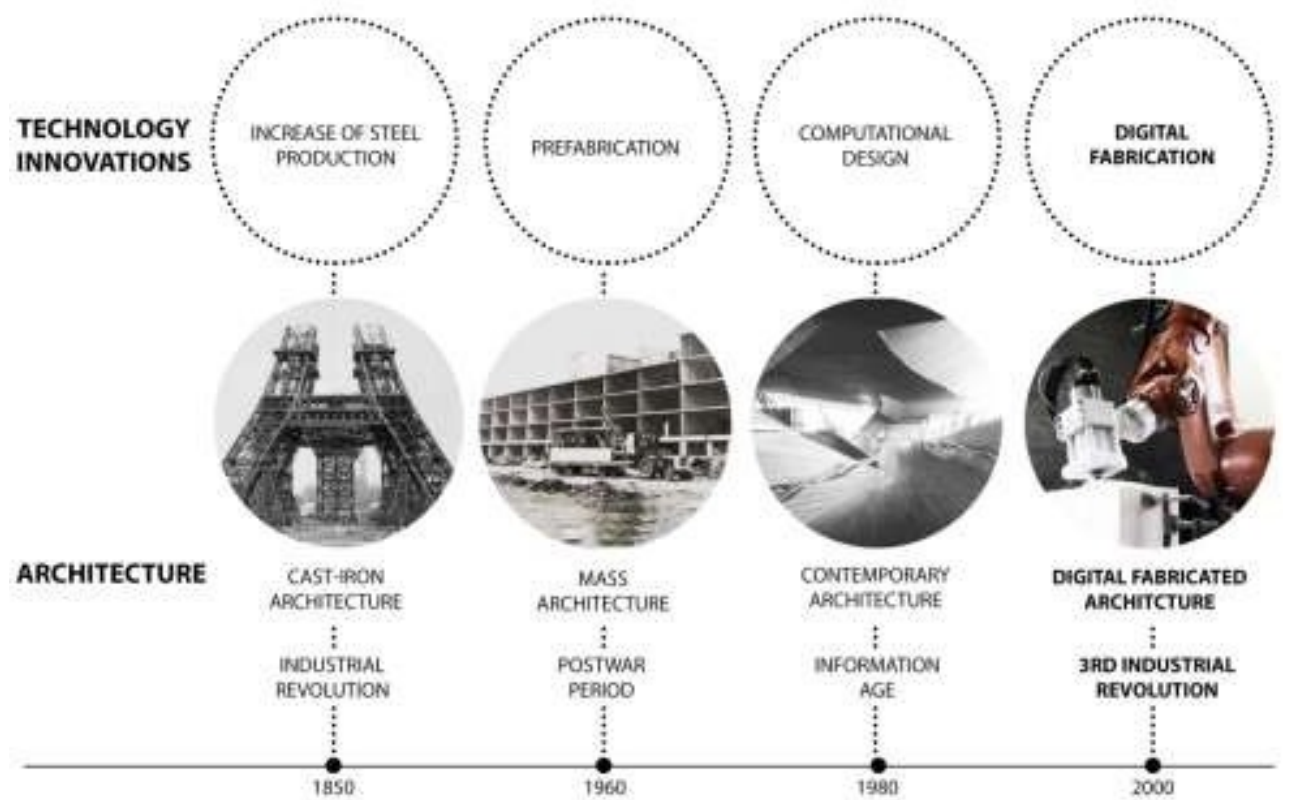

Fig 5: courtesy of COdesignLab

\section{Case study: the "Vele" of Scampia}

Scampia is a neighborhood located in the north suburb of the city of Naples, born after

WW2, characterized by a large number of social housing estates, among which "le vele".

These were built between 1962 and 1975 , covering $14000 \mathrm{~m}^{2}$ and host about 6500 inhabitants ( some abusive ) in 1300 residential units .

Designed by architect Franz Di Salvo, the vele from the theoretical assumptions of the mega structural utopia of the $60 \mathrm{~s}$ in response to the amount of housing 
needs according to the large increase of population.

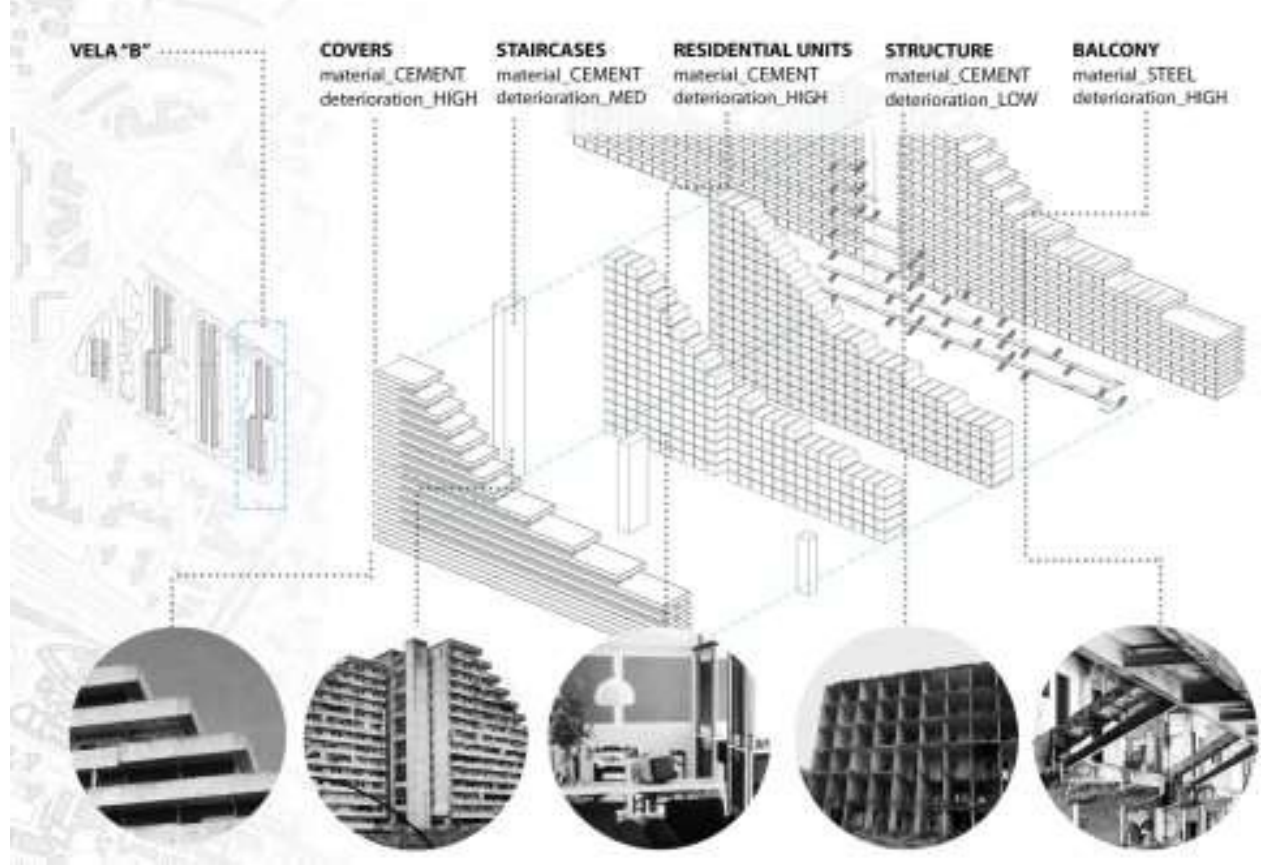

Fig6: the Vele elements anlaysis - courtesy of COdesignLab

Nowadays "le vele " are in a high degraded situation caused by several factors (figure $3)$.

First of all the discrepancy between the original project and the execution has caused a series of technical and constructive problems:

- the very low flexibility of spaces use, due to the changing of the structural system from a lighter "gantry" system designed by engineer Riccardo Morandi to a heavier "tunnel" system.

- in the residential units and trough the balconies the daylight levels don't respect the values given by the UNI 10.380 - 13/05/2013, caused by the reduction of the space between the parallel wings of the building from $10,80 \mathrm{~m}$ to $8,40 \mathrm{~m}$ (figure 4).

The daylight level is calculated with Autodesk - Ecotect. The simulation input are: local weather data (Naples, latitude $41,8^{\circ}$, longitude $12,6^{\circ}$, design sky 8500 lux) and the geometry of residential unit. the result of the simulation reveals the average values of each room of the residential unit. are lower than the value given by the Italian law (UNI 10.380 / 13-05/2013).

- the mono-functionality and the overcrowding of the residences, due to the fact that they were built only 7 of the 8 buildings. 
In addition to these problems there are those related to the social community that was settled in the estate after the 1980 earthquake, which was made of a mono classist population of proletarians characterized by an high unemployment rate.

These factors have constituted fertile ground for the proliferation of crime, which on one side has taken advantage of social degradation to recruit mainly young boys within their ranks, and on the other side has exploited the technical issues of the buildings to transform them in drug dealing strongholds.

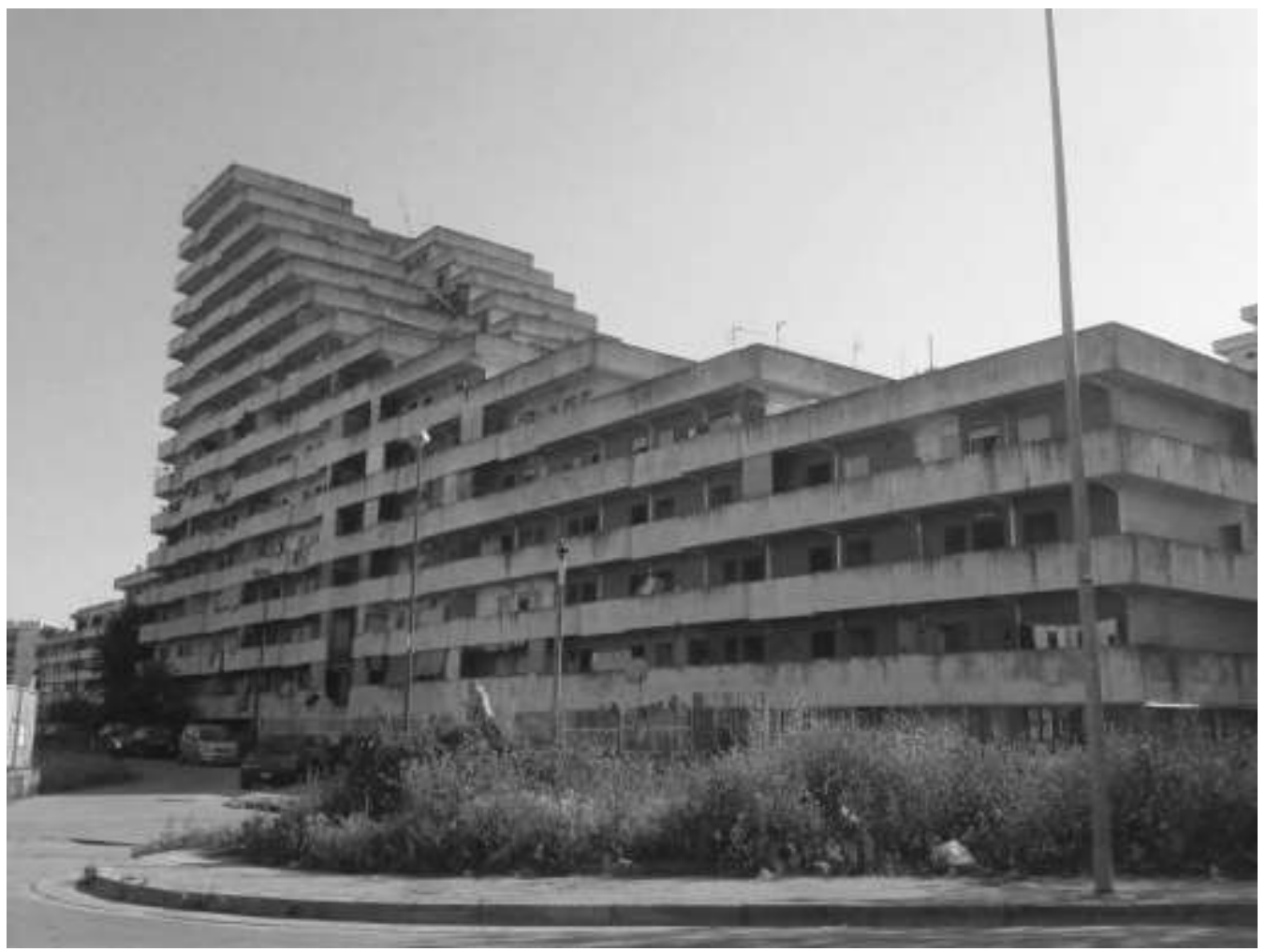

Fig7: the Vele buiding - courtesy of COdesignLab 

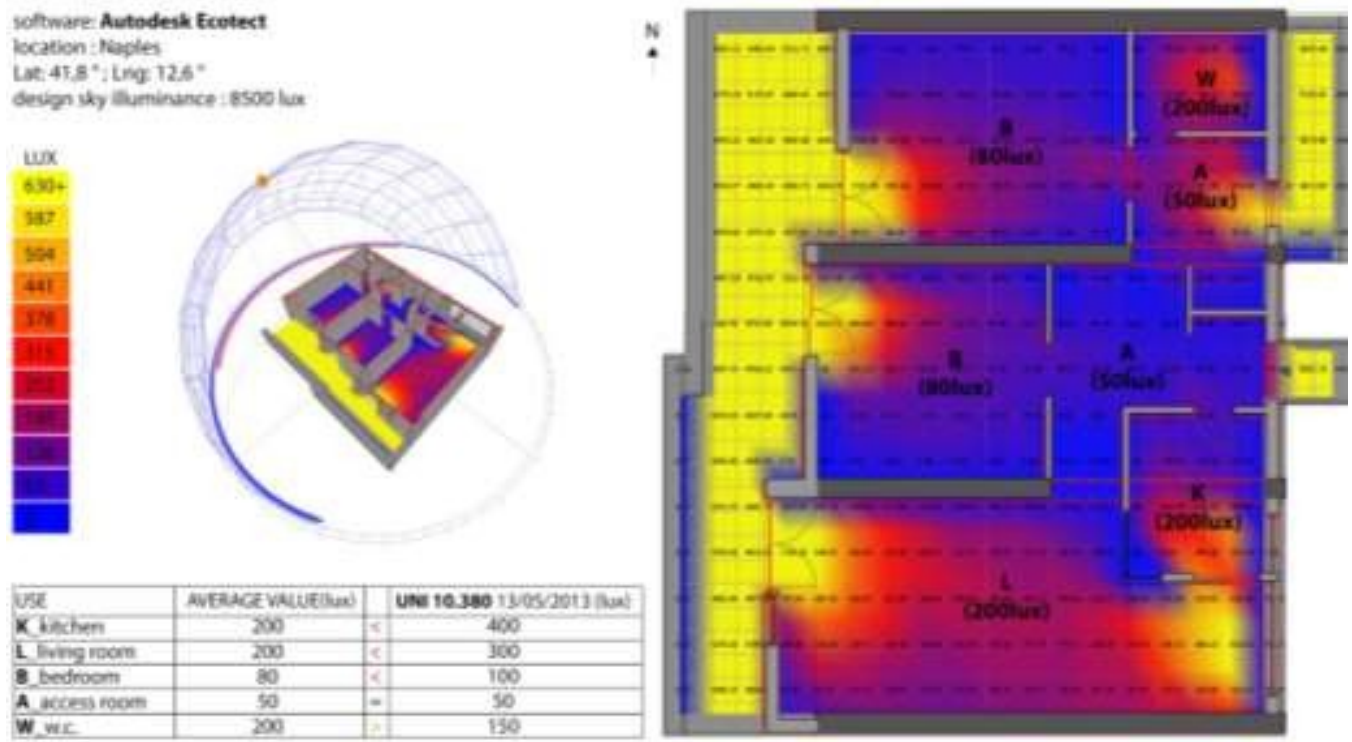

Fig8:environmental analysis of the Vele buiding - courtesy of COdesignLab

\section{design process}

The decay of the building evident the need for an intervention aimed at improving the performance from different points of view.

In this sense the carried out analysis represent the design process input defining its performative criteria.

First of all the big data coming from the social analysis show the need of differentiating the use of the residential spaces which must fit specifically to the users , desaturating the overcrowded areas and implanting common and productive spaces , in order to gain a social and programmatic mixitè.

The environmental analysis show the lack of natural light access (daylight level). 


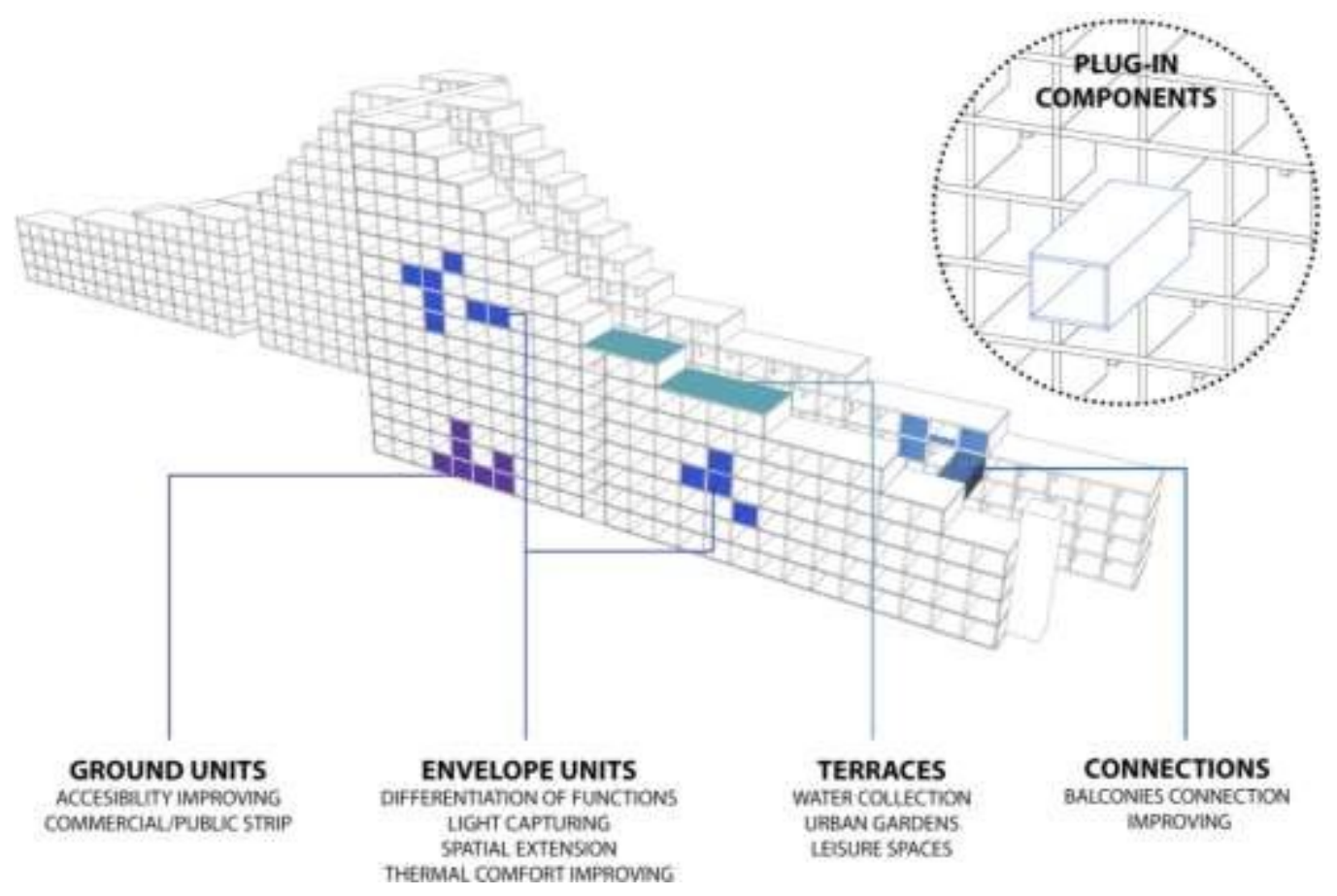

Fig9:Hacking Gomorra project strategy - courtesy ofCOdesignLab

The design output resulting from the performative criteria consists in genotypic $3 \mathrm{~d}$ printed plug-in structural component which can be implanted in the preexistent structure and accomplish programmatic (user specific ergonomic) technical (vertical and horizontal connections) and environmental (improving of the thermal performance / passive cooling ventilation/natural light access) issues.

\section{material systems}

The material system choice depends on an analysis of a series of experiences about the additive manufacturing technology with liquid materials for big scale $3 \mathrm{~d}$ printing.

- Behrokh Khoshnevis, professor of Industrial \& Systems Engineering and Civil \& Environmental Engineering and Director of the Center for Rapid Automated Fabrication Technologies (CRAFT) at the University of Southern California, within the project of Countour Crafting has experienced the use of fiber reinforced cement mortars, with a 
compressive strength more than three times than the conventional concrete $(10,000 \mathrm{psi}$, versus 3,000 psi).

- Amalgamma, a student team from the Bartlett University, are developing an hybrid system which uses the extrusion technology mixed to the powder bed technology . The ready mixed cement is extruded ( FDM ) by a robotic arm and the external surface is treated ( from another tool on the same robotic arm ) whith granular powder which mixed to a binder can improve the strength, allowing more complex geometries.

- Emerging Objects has experimented a polymer cement mortar, which is subsequently treated whit sand powder.

These examples show us how the optimized cement mortar for $3 \mathrm{~d}$ printing must be fiber reinforced and processed with chemicals ( such as adhesives and hydrators ) or natural substances ( granular powders ) to improve the structural strength .

The $3 \mathrm{~d}$ printing concrete performances are well synthesized by A.Thorpe in " Mix design and fresh properties for high-performance printing concrete" in which are identified four key characteristics :

(1) Pumpability - The ease and reliability with which material is moved through the delivery system;

(2) Printability - The ease and reliability of depositing material through a deposition device;

(3) Buildability - The resistance of deposited wet material to deformation under load; and

(4) Open time - The period where the above properties are consistent within acceptable tolerances. 


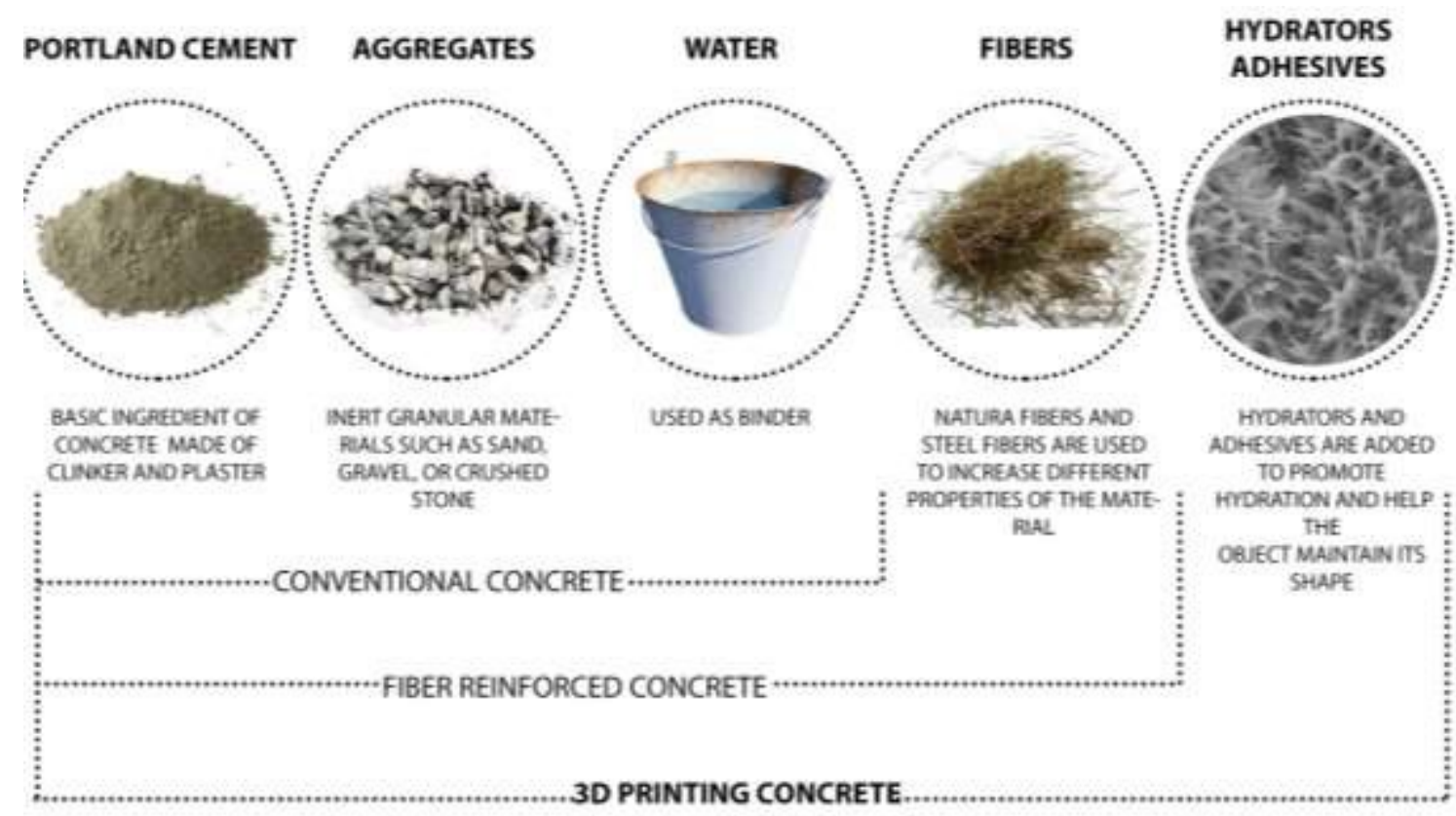

Fig 10:material systems Hacking Gomorra project - courtesy of COdesignLab

\section{parametric form finding}

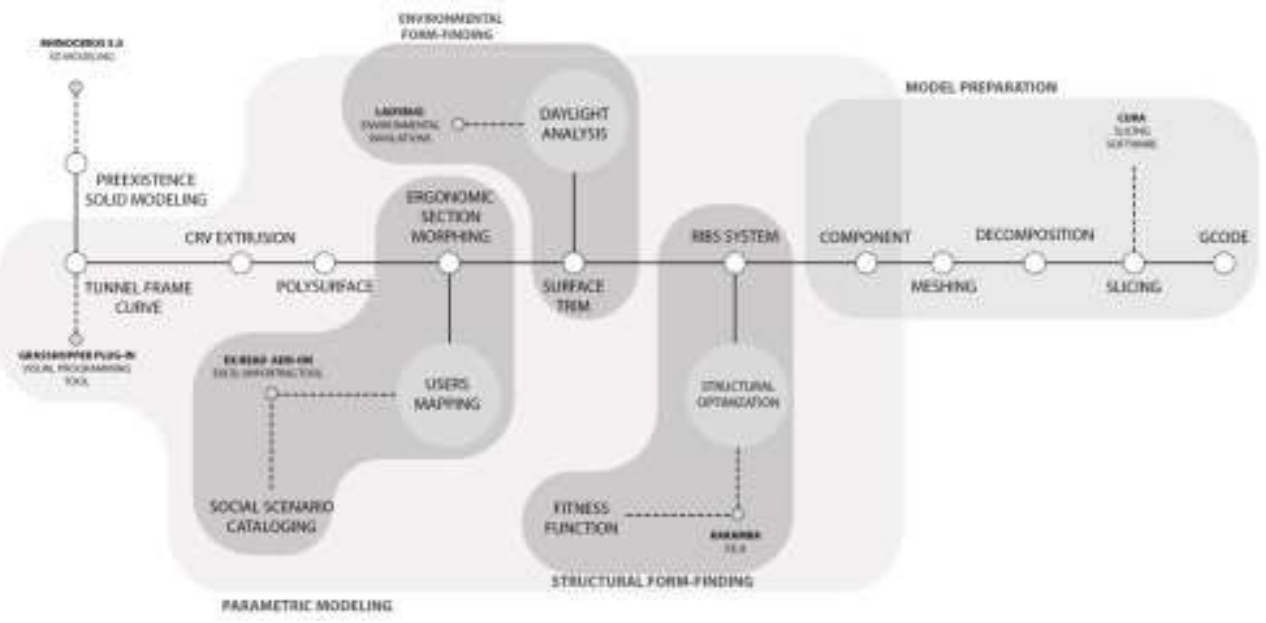

Fig 11: Flow chart of digital process Hacking Gomorra project - courtesy of COdesignLab

Form - finding, as pioneered by Frei Otto, is a design technique that utilizes the self-

organization of material systems under the influence of extrinsic forces. 
The form-finding processes for the genotypic model can be physically modelled and simulated through digital dynamic relaxation. The latter involves iterative calculations based on

- internal ergonomic

- environmental slicing

- structural ribs .

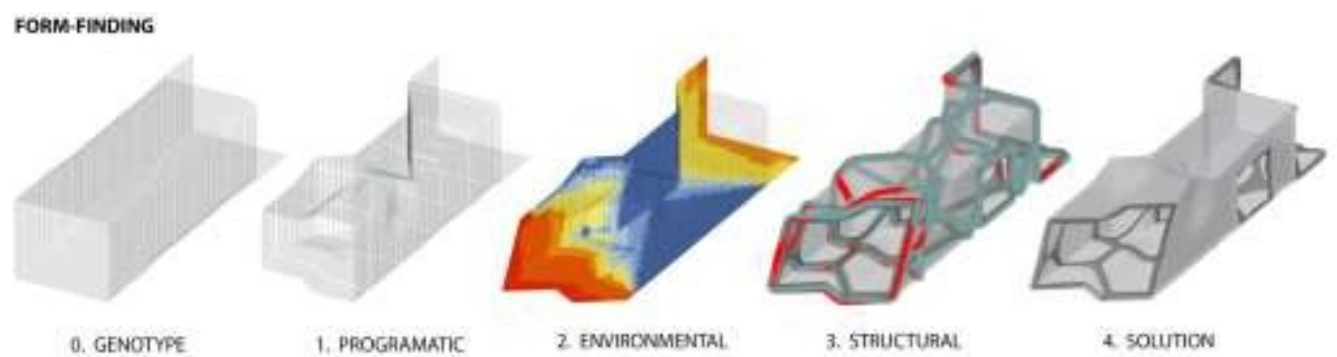

Fig 12: form finding strategy Hacking Gomorra project - courtesy of COdesignLab

The big data concerning the users have been catalogued and ordered in a matrix which has been imported in the parametric modelling software Grasshopper ("ex -read" grasshopper add-on) to map the cells of the structure, crossing the data with the programmatic layout of the spaces. This informs the site/user specific ergonomics of the internal part of the components trough a loft of prototypical sections. In this sense, the software becomes a user-driven design tool. 


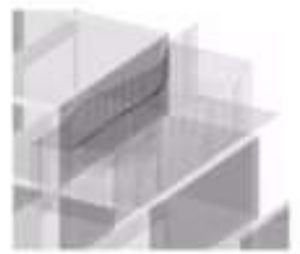

KITCHEN

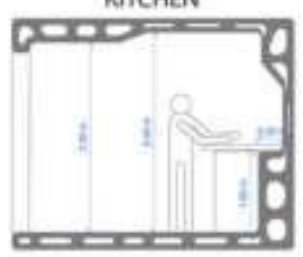

BEDROOM

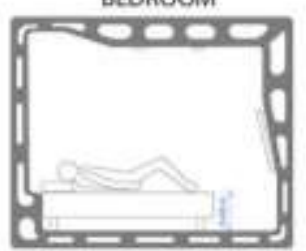

BATHROOM

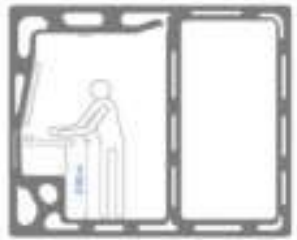

WORKSPACE

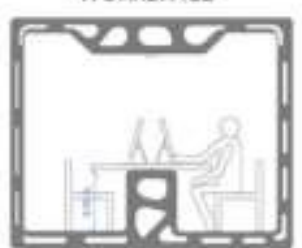

BEDROOM

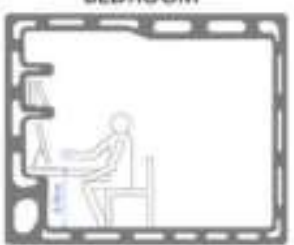

BEDAOOM

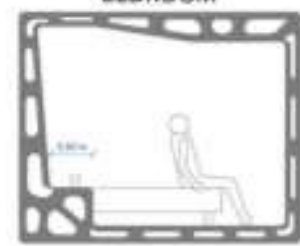

OFFICE

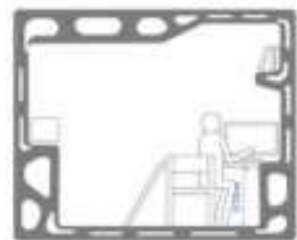

BEDROOM

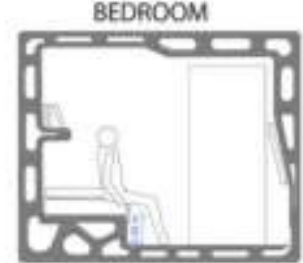

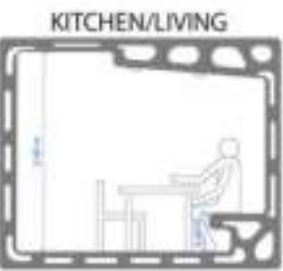

WORKSPACE

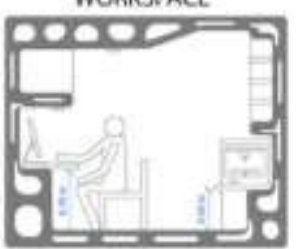

LIVING ROOM

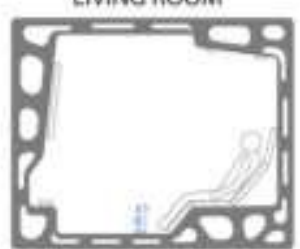

Fig 13: genotypical sections Hacking Gomorra project - courtesy of COdesignLab

The environmental data concerning the daylight level values are isolated for each of the structure cells in order to compute (using Galapagos and Ladybug plug-ins ) a series of possible variations of the external projection of the components to optimize the natural light access. The access of natural light is controlled through the rotation of an xz plane that cut the genotypic according the $\mathrm{x}$ axes and according the $\mathrm{z}$ axes. The combination of both the movement let us to obtain a façade that change respect on its specific position in the building. 


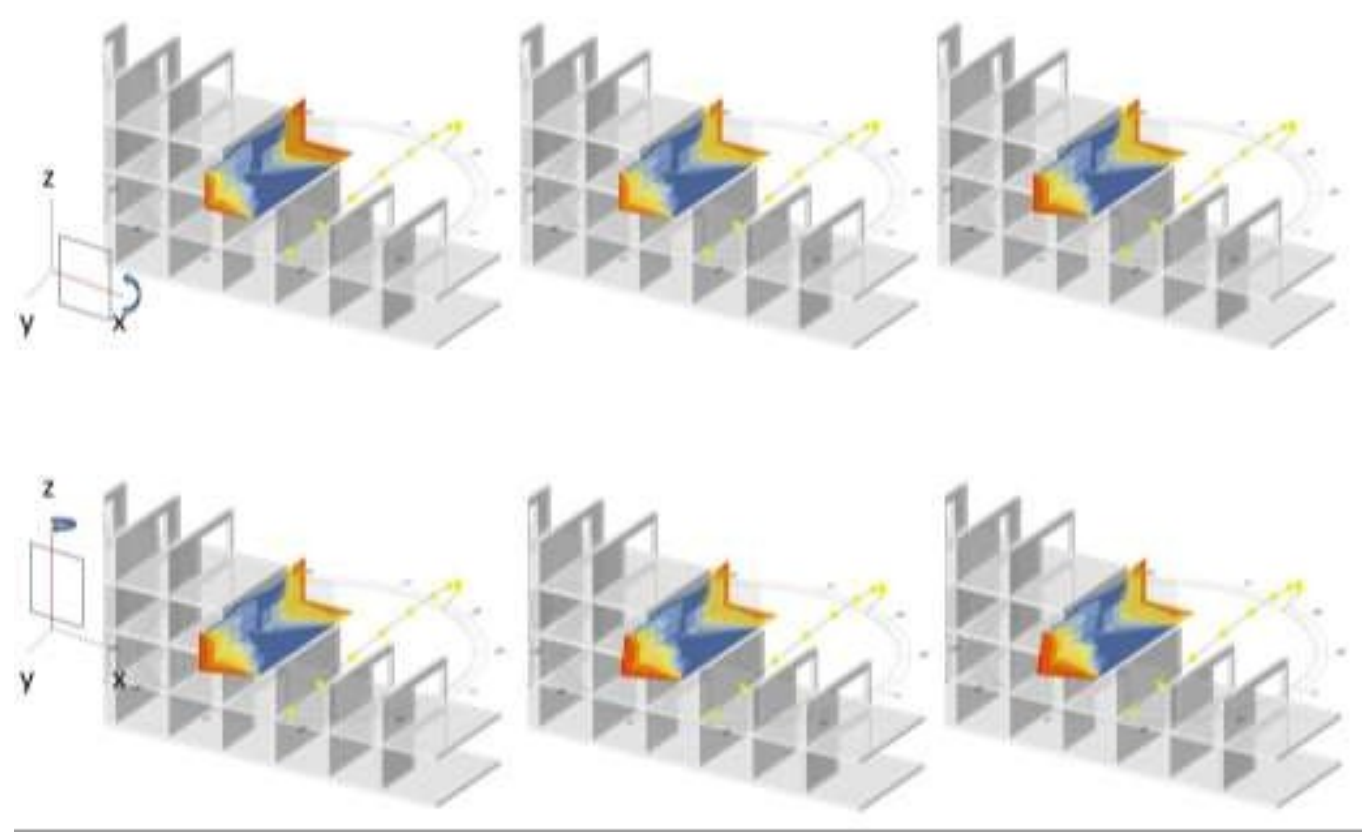

Fig 14: daylight optimization - Hacking Gomorra project - courtesy of COdesignLab

The structural optimization is driven by a subtraction of material and a variation of material section respect on the path of the main stress.

Using Karamba ( FEA plug-in of Grasshopper ) a series of structural ribs configurations have been analyzed having has constraints the edges of the brep and the angle between the ribs and the $3 \mathrm{~d}$ printing plan and as variables the porosity of the ribs system.

The form-finding was driven by the approximation of the fitness function:

$\mathrm{f}=$ weight + axial stress $->\min$

to optimize the weight and the axial stress of the components . 


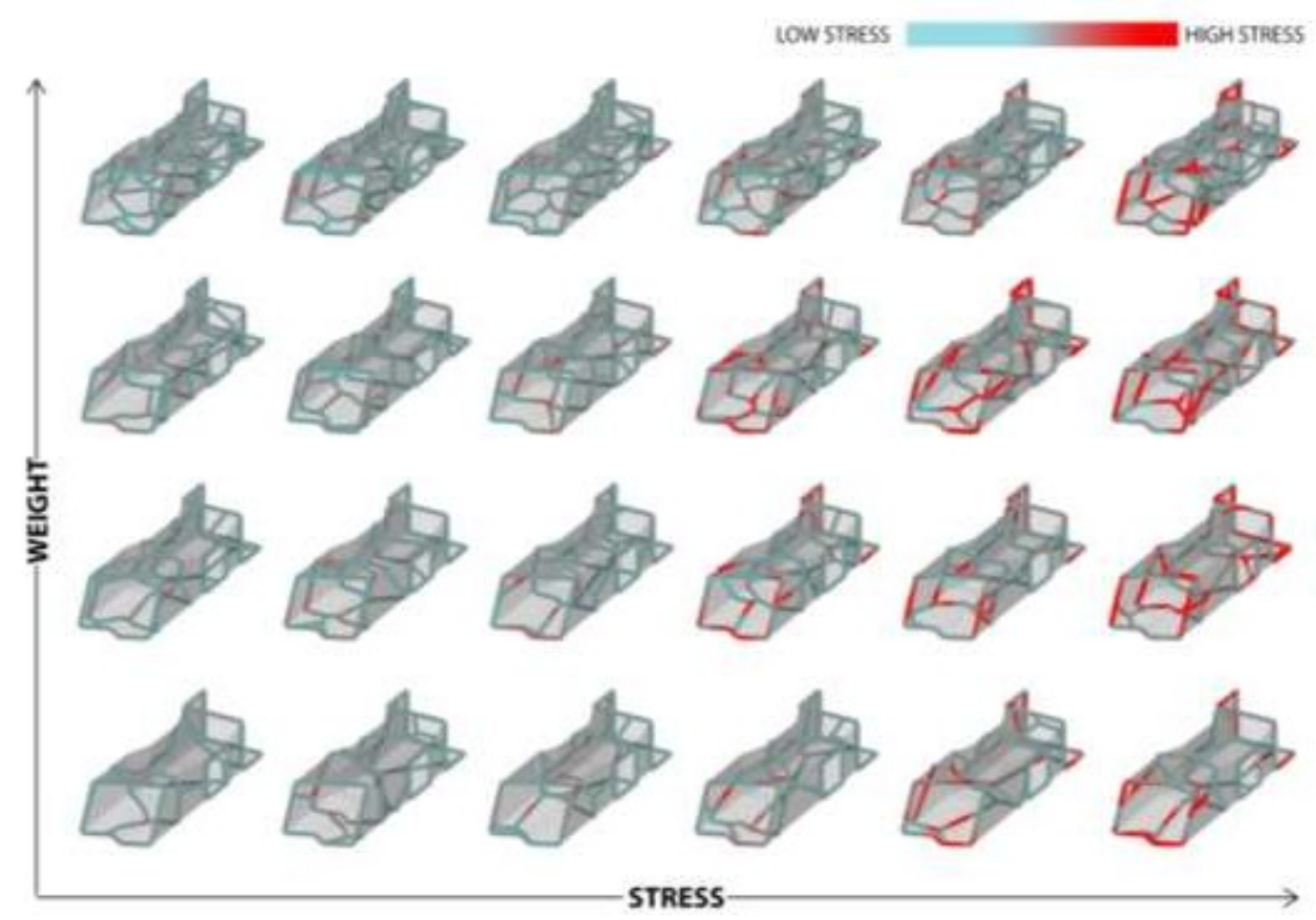

Fig 15: structural optimisation - Hacking Gomorra project - courtesy of COdesignLab

\section{performative testing (simulations)}

The generated forms have been tested to verify the improvement of the environmental and structural performances.

- the daylight factor analysis show the increase of the diffuse light in the internal space of the $20 \%$.

- the structural testing with Abaqus (FEA software ) show the efficiency of the ribs system which optimize the axial stress and the low weight of the component. 

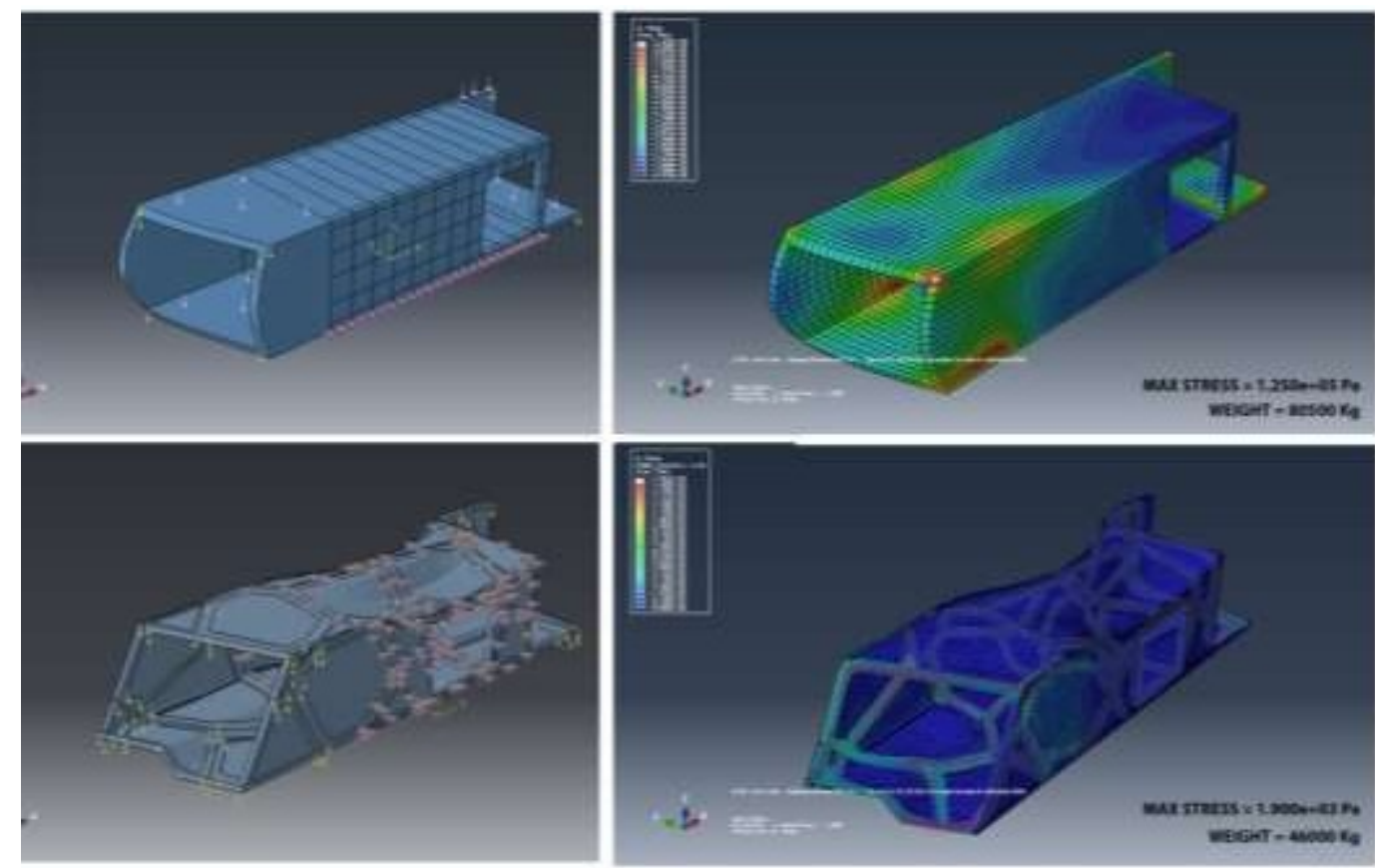

Fig 16: structural comparative analysis- Hacking Gomorra project - courtesy of COdesignLab

\section{fabrication process (protocols)}

The digital fabrication process is made of three steps:

- model preparation

the component $3 \mathrm{~d}$ models are decomposed to fit the $3 \mathrm{~d}$ printing bed ad converted to meshes (.stl files ). After that they were sliced (slicing phase is fundamental for the quality and the time of the print ) setting the printing parameters according to the testing of the print material. The printing paths were optimized to reduce the flow disruptions. $3 \mathrm{~d}$ printing The printing codes are sent to the control panel of the $\mathrm{CNC}$ machine, which deposes the material for successive layers. The right ratio of speed, and the water percent in clay is fundamental for the surface accuracy of the print. The $3 \mathrm{~d}$ printed component's surfaces can be finished with the adding of granular powder to ensure the structural resistance. 


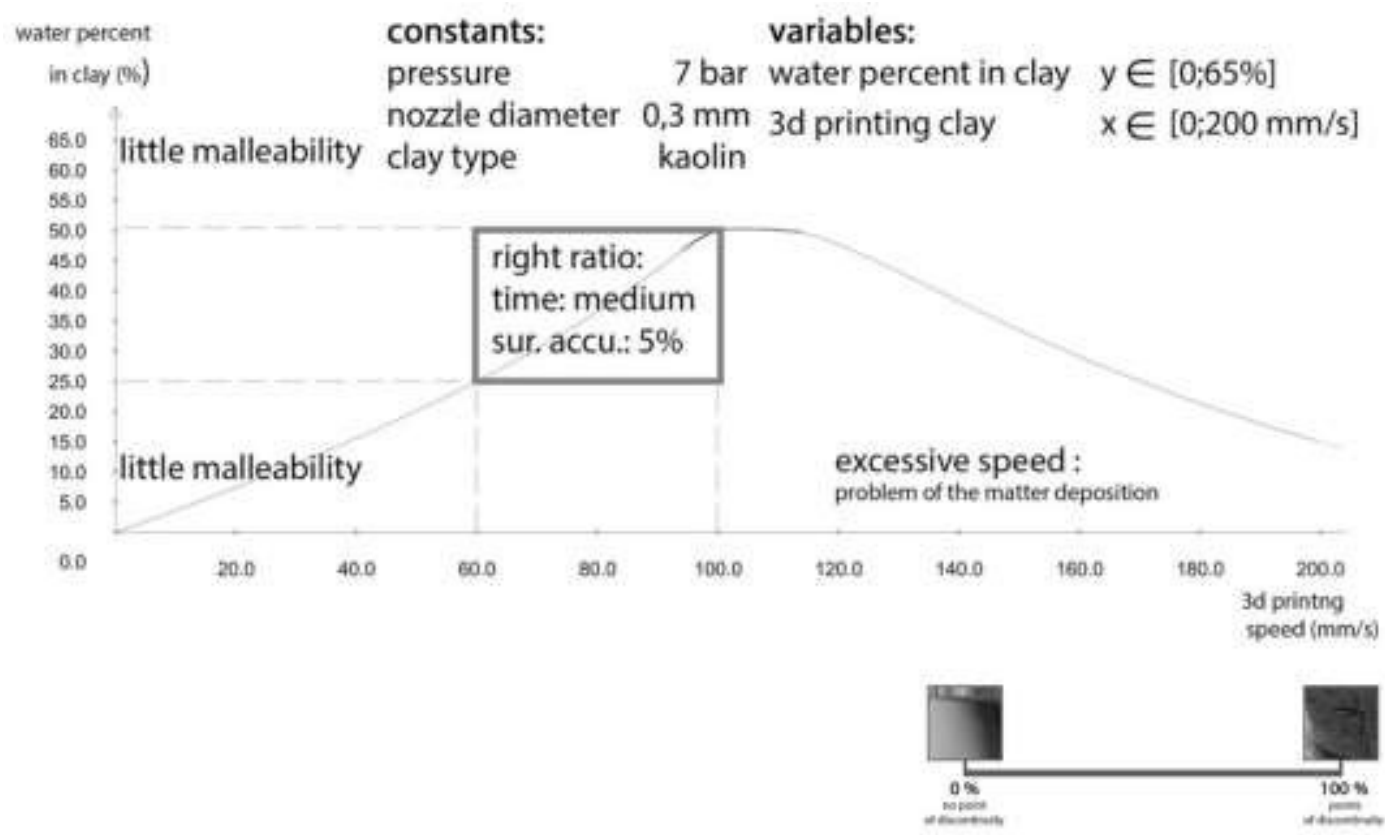

Fig 17: 3D printing quality study - Hacking Gomorra project - courtesy of COdesignLab

\begin{tabular}{|c|c|c|c|c|c|c|c|}
\hline 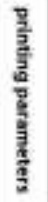 & $\begin{array}{l}\text { geometrical } \\
\text { configuration }\end{array}$ & ${ }^{1}$ & 2 & एक्स & (4) & (2) & 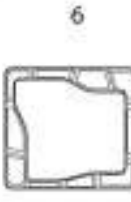 \\
\hline & internal infill & $20 \%$ & $60 \%$ & $\operatorname{son}$ & $40 \%$ & $30 \%$ & 2046 \\
\hline A & $\begin{array}{l}\text { speed_20 mm/s } \\
\text { flow rate. } 10006 \\
\text { pressures } 8 \text { bs } \\
\text { malleatbility. }\end{array}$ & $\begin{aligned} s .3: & =10 \% \\
t & =\text { high }\end{aligned}$ & $\begin{array}{l}s .2=23 \% \\
t=h i g h\end{array}$ & $\begin{array}{l}\text { s.a. }=28 \% 5 \\
t=\text { bigh }\end{array}$ & $\begin{array}{l}s a_{t}=48 \% 6 \\
t=h i g h\end{array}$ & $\begin{array}{l}s . a x=314 t \\
t=\text { med }\end{array}$ & $\begin{array}{l}\text { sa }=124 t \\
t=\text { med }\end{array}$ \\
\hline 8 & 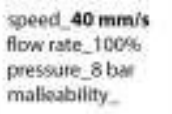 & $\begin{array}{l}\text { s.a. }=256 \\
t=\text { high }\end{array}$ & $\begin{array}{l}s A=26 \% \\
t=\text { high }\end{array}$ & $\begin{array}{l}s \mathrm{~s}=30 \mathrm{~B} s \\
t=\bmod \end{array}$ & $\begin{array}{l}s \mathrm{~s}_{\mathrm{i}}=33 \% \mathrm{~W} \\
\mathrm{t}=\operatorname{mied}\end{array}$ & $\begin{array}{l}3 .: A=4195 \\
t=\bmod \end{array}$ & $\begin{array}{c}\mathrm{sa}=2 \mathrm{bl} \\
\mathrm{t}=\mathrm{law}\end{array}$ \\
\hline c & $\begin{array}{l}\text { speed_60 mm/s } \\
\text { flow rate } 10056 \\
\text { pressure } 8 \mathrm{bs} \\
\text { malleability }\end{array}$ & $\begin{array}{l}\text { sax }=446 \\
t=\text { high }\end{array}$ & $\begin{array}{l}5 x=1096 \\
t=\text { med }\end{array}$ & $\begin{array}{l}5 \mathrm{~s}=27 \mathrm{~b} \\
t=\text { med }\end{array}$ & $\begin{array}{c}s_{1}=32 \% \\
t=\text { law }\end{array}$ & $\begin{array}{c}5 x=3006 \\
t=\text { low }\end{array}$ & $\begin{array}{c}c_{i}=283 \mathrm{~h} \\
t=\text { bow }\end{array}$ \\
\hline 0 & 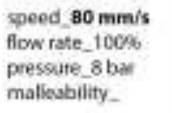 & $\begin{array}{l}s a=5 \% \\
t=\text { med }\end{array}$ & $\begin{array}{l}s . A=1996 \\
t=\operatorname{med}\end{array}$ & $\begin{array}{c}s a=47 \% \\
t=\text { low }\end{array}$ & $\begin{array}{l}s \mathrm{a}:=54 \% \\
t=\text { law }\end{array}$ & $\begin{array}{c}S A=4390 \\
t=10 N\end{array}$ & $\begin{array}{c}s a=57 \mathrm{w} \\
t=10 w\end{array}$ \\
\hline E & $\begin{array}{l}\text { soeed_100 mm/s } \\
\text { flow rate_100\% } \\
\text { pressure_8 bot } \\
\text { malleability. }\end{array}$ & $\begin{array}{l}s \mathrm{~s}=840 \\
t=10 \mathrm{WW}\end{array}$ & $\begin{array}{l}s .1=10 \% t \\
t=10 \mathrm{w}\end{array}$ & $\begin{array}{l}\text { s.a }=139 \% \\
t=\text { low }\end{array}$ & $\begin{array}{l}\mathrm{sa}, \mathrm{a}=36 \% \\
t=\operatorname{low}\end{array}$ & $\begin{array}{l}s .2=40 \mathrm{mt} \\
t=l o \mathrm{~W}\end{array}$ & $\begin{array}{l}\text { s.a. }=6.24 \mathrm{i} \\
t=\mathrm{kow}\end{array}$ \\
\hline
\end{tabular}

t $=$ print time

Fig 19: 3D printing matrix of evaluation - Hacking Gomorra project - courtesy of COdesignLab 

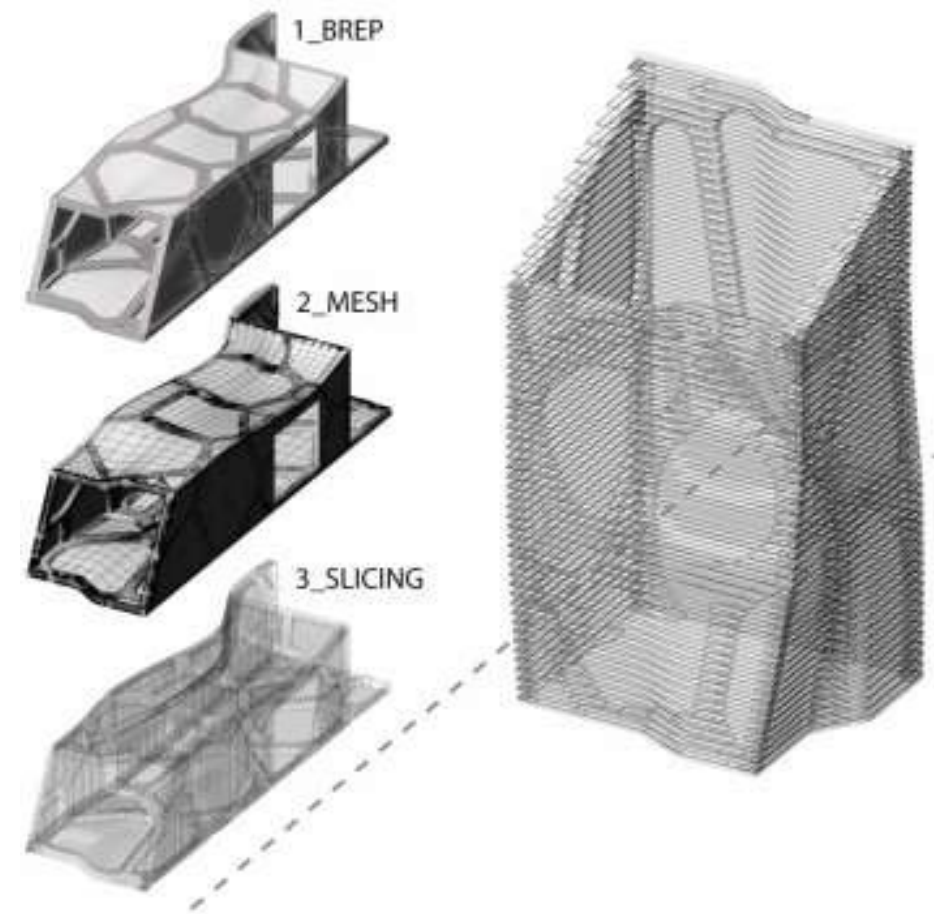

4_DECOMPOSITION

Fig 20: 3D printing modeling - Hacking Gomorra project - courtesy ofCOdesignLab

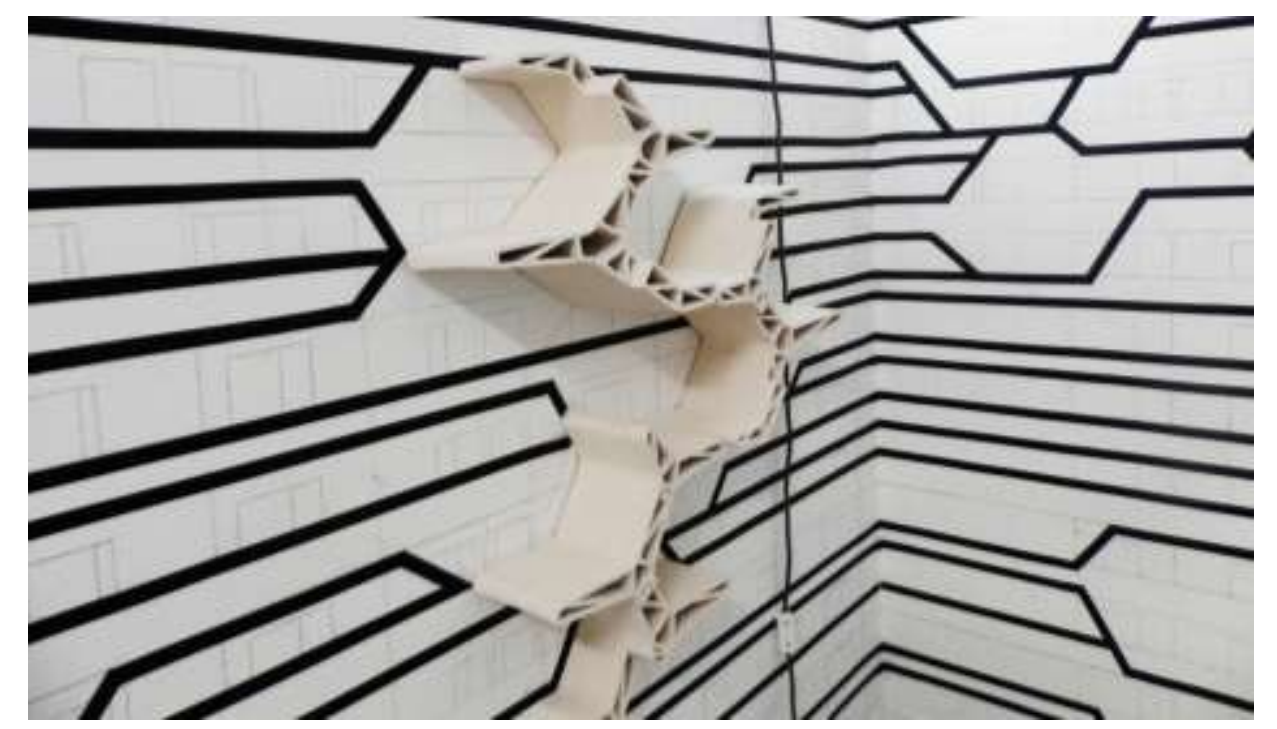

Fig 21: 3D printed prototypes - Hacking Gomorra project - courtesy ofCOdesignLab 


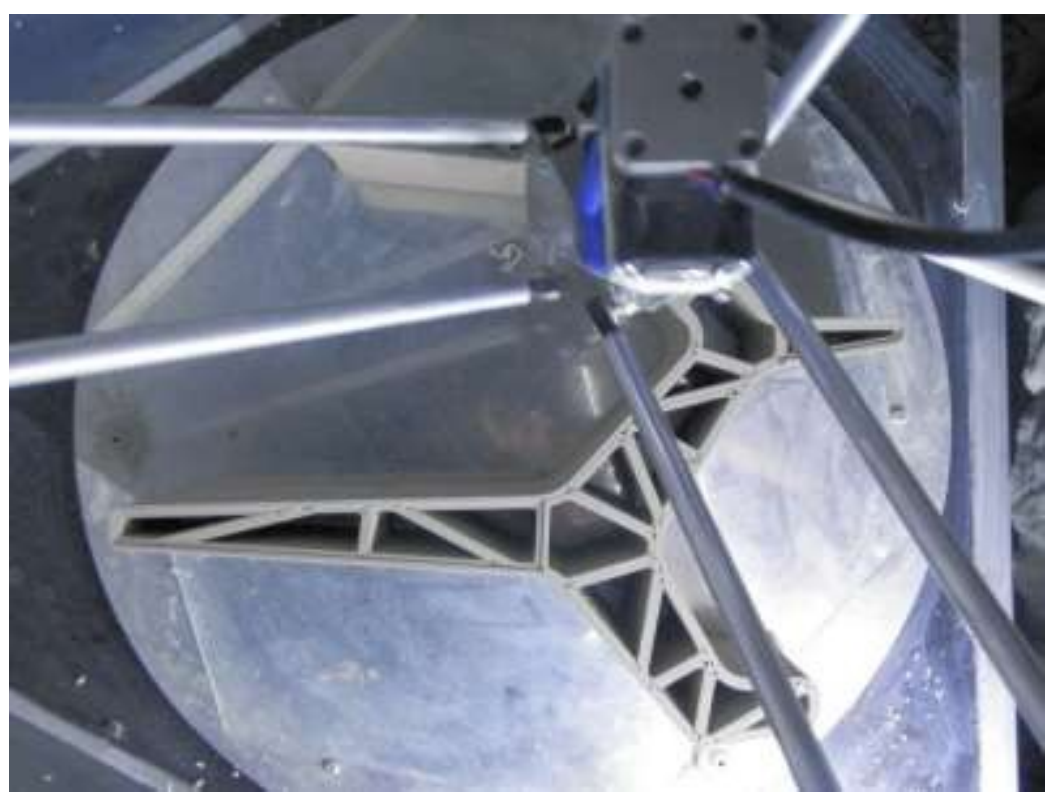

Fig 22: 3D printing process - Hacking Gomorra project - courtesy of COdesignLab

\section{.architectural assembly systems}

the first step of the construction provides the disposal of some of the cement elements of the preexistence. The resulting material re-enters the production cycle of the new $3 \mathrm{~d}$ printed components forming the base of the extruding mortar.

In this sense, the global added weight of the intervention is about equal to the preexistence in order to leave unchanged the structural operation in line with the anti-seismic regulations. The $3 \mathrm{~d}$ printing occurs on site, reducing transportation costs $(0 \mathrm{~km}$ materials $)$, through the use of robotic arms working on a prepared area of the construction site.

Subsequently the components are positioned by other robots in the structural grid and assembled using steel joint.

This allows the simplicity of the maintenance and the replacement of the components which can be "updated" emulating an hardware-software system. 

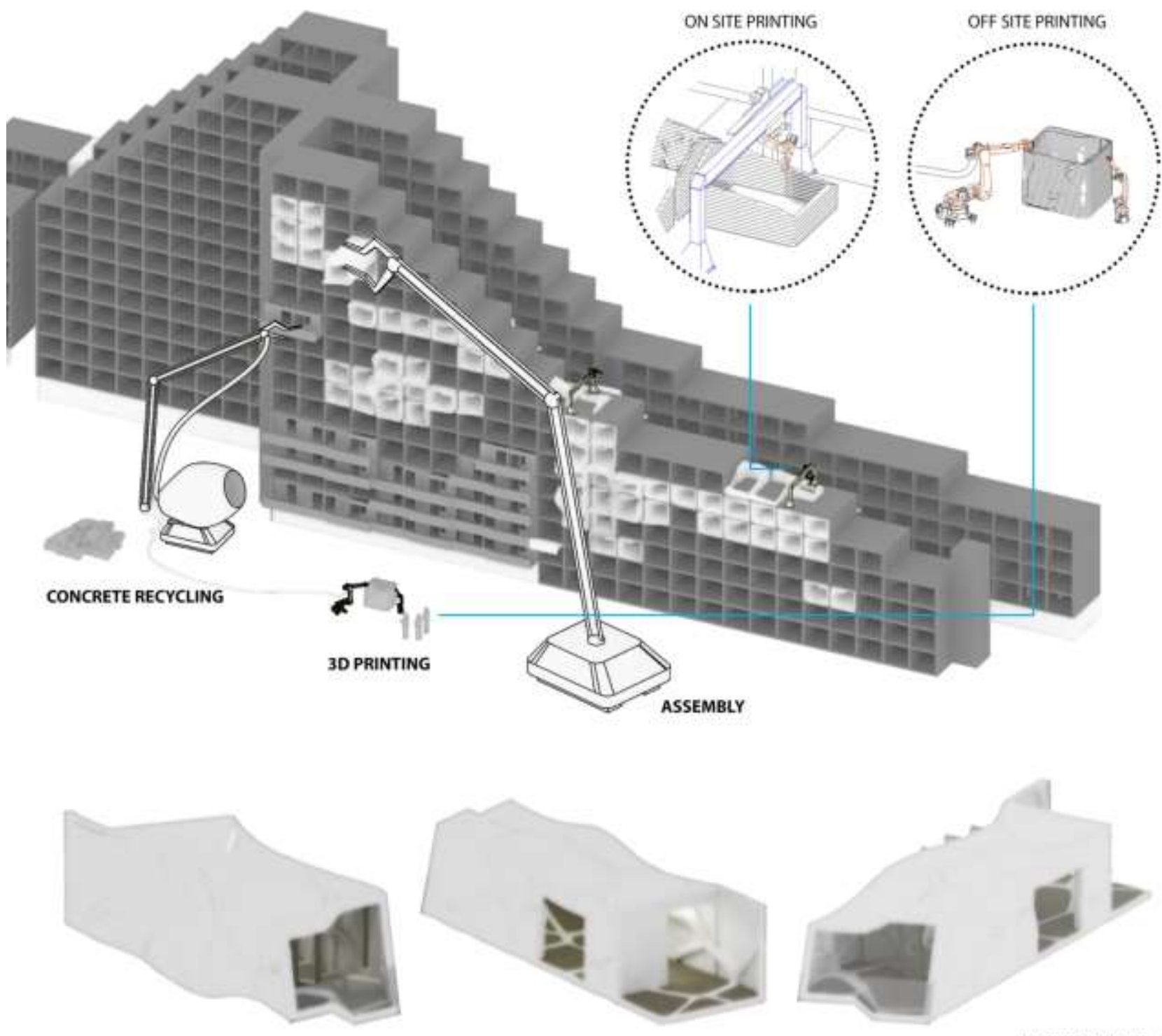

EXTERNAL VIEWS
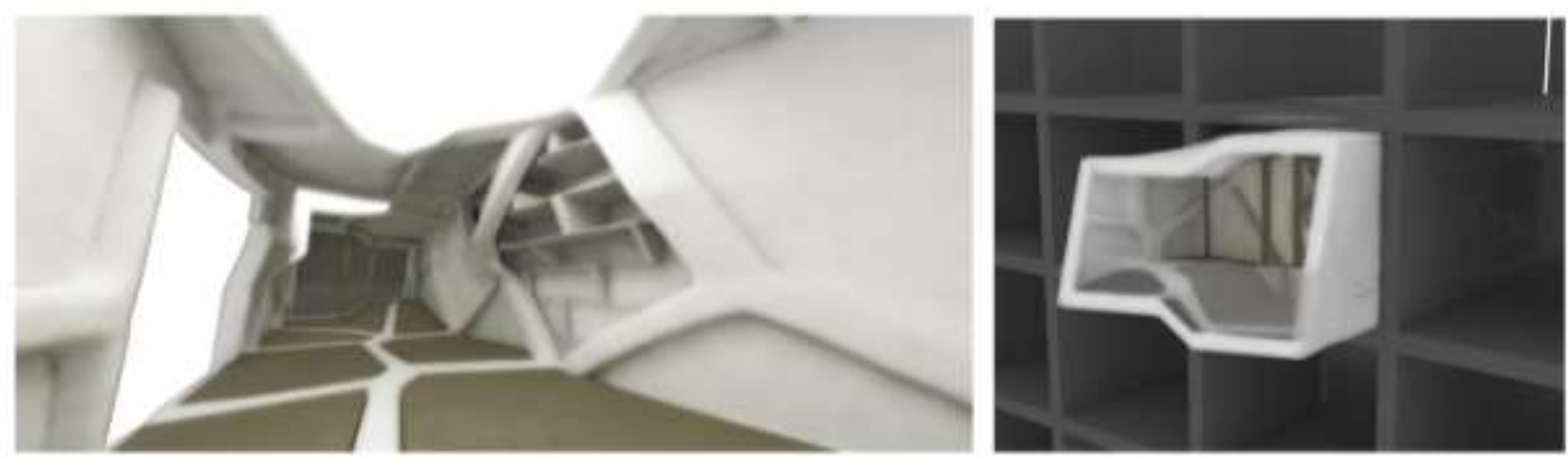

Fig 23: smart construction process - Hacking Gomorra project - courtesy of COdesignLab 


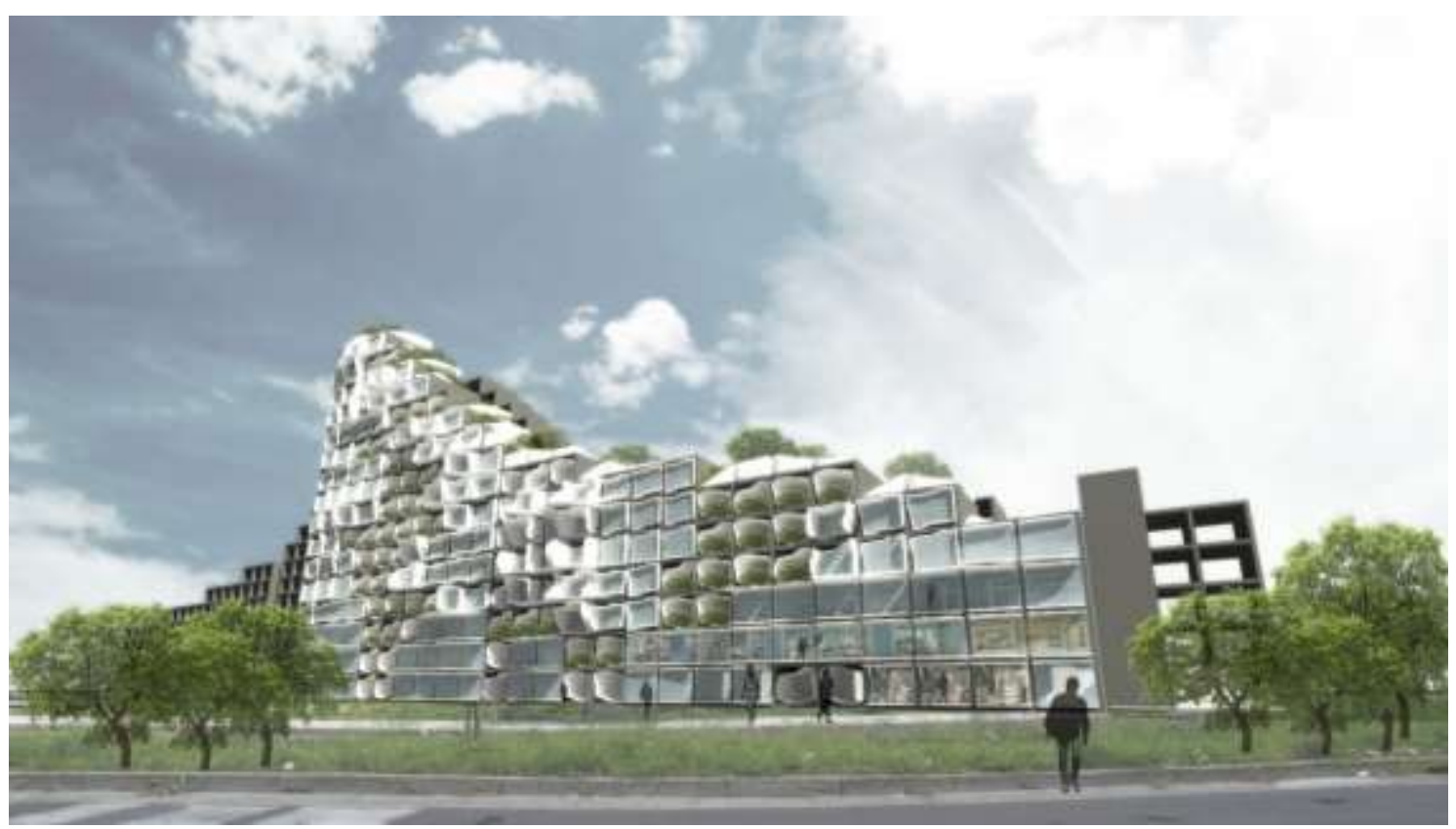

Fig 24: architectural view - Hacking Gomorra project - courtesy of COdesignLab

\section{References}

- W. von Goethe, "indeen über organische bildung" (1806), published on Computational Design Thinking - AD Reader, Wiley (2011)

-M. Carpo, “The Digital Turn in Architecture 1992-2012”, Wiley (2012)

-M. Weinstock, “The Architecture of Emergence”, Wiley (2010)

-M. Wolfler Calvo, Archigram / Metabolism - Clean editions (2007)

- C. Parent and P. Virilio, 'Function of the oblique' (1963-1969) - AA Publications (1996)

-C. Alexander, Systems Generating Systems- December issue nº 7/8- Architectural Design (1968)

-R. Hague, I. Campbell, P. Dickens, "Implications on Design of Rapid Manufacturing." Proceedings of the Institution of Mechanical Engineers, Part C, Journal of Mechanical Engineering Science Vol 217 (no. 1) (2003) 25-30.

-T. Bonwetsch, F. Gramazio, M. Kohler, Digitally Fabricating Non-Standardised Brick Walls, Paper presented at the ManuBuild conference proceedings, Rotterdam, 2007.

- S. Lim, T. Le, J. Webster, R. Buswell, S. Austin, A. Gibb, T. Thorpe, Fabricating construction components using layer manufacturing technology, (GICC'09), Paper presented at the Global Innovation in Construction Conference, Loughborough University, Leicestershire, UK, 2009, 13-16 September, 2009.

- Khoshnevis Behrokh, Bukkapatnam Satish, Kwon Hongkyu, Saito Jason, Experimental 
investigation of contour crafting using ceramics materials, Rapid Prototyping Journal Vol 7 (no. 1) (2001) 32-41.

- B. Khoshnevis, Automated construction by Contour Crafting—related robotics and information sciences, Automation in Construction Special Issue: The Best of ISARC 200213 (1) (2004) 5-19

- Kolarevic, B. (2000). Digital Architectures. In Proceedings of the ACADIA 2000 Conference, eds. M. Clayton and G. Vasquez. Washington, DC: Catholic University of America.

- Pegna, J., Construction automation: Are we solving the wrong problem?, RPI/RDRC Technical Report 92010, 1992.

- Maxwell, J.L., Pegna, J. and Hill, E., Gas-phase laser induced pyrolysis of tapered microstructures, Proc. Solid

Freeform Fabrication Symp., Austin, Texas, Aug. 7-9, 1995.

- Pegna, J., Exploratory investigation of layered fabrication Automation Con\$, Boston, Massachusetts, Sept. 17-20, 1995.

-Irénée Scalbert, A

- Gaetano Fusco, Francesco Di Salvo. Opere e progetti, Clean Edizioni 